\title{
Armazenamento de tomate cultivar “Cronus” em função do estádio de maturação e da temperatura
}

\author{
Storage of tomato cultivar 'Cronus’ as a function of ripening stage and temperature
}

\author{
Auri Brackmann ${ }^{\mathrm{I}}$ Cristiano André Steffens" Jerônimo Luiz Andriolo ${ }^{\mathrm{III}}$ \\ Josuel Alfredo Vilela Pinto
}

\section{RESUMO}

\begin{abstract}
O objetivo deste trabalho foi avaliar o efeito do estádio de maturação e de diferentes temperaturas de armazenamento na manutenção das qualidades físicoquímicas do tomate cultivar "Cronus". Os tratamentos avaliados foram uma combinação entre os fatores estádio de maturação, parcialmente maduro e maduro e temperatura de armazenamento de $6,8,10$ e $12^{\circ} \mathrm{C}$. Os frutos foram armazenados em minicâmaras experimentais com umidade relativa em torno de $90 \%$. Após 30 dias de armazenamento mais dois de exposição dos frutos a $20^{\circ} \mathrm{C}$, não foram observadas interações entre os fatores estádio de maturação e temperatura de armazenamento nos parâmetros avaliados. As temperaturas de 6 e $8^{\circ} \mathrm{C}$ apresentaram frutos com maior firmeza de polpa. Entretanto, nestas temperaturas, a incidência de frutos com dano pelo frio, rachados e podres foi mais elevada. Os parâmetros sólidos solúveis totais e acidez titulável não apresentaram diferença significativa entre os tratamentos. Verificou-se que os frutos armazenados no estádio de maturação parcialmente maduro apresentaram maior firmeza de polpa e menor incidência de podridões e rachaduras. $O$ estádio de maturação não influenciou a suscetibilidade a danos por baixa temperatura.
\end{abstract}

Palavras-chave: pós-colheita, dano pelo frio, Lycopersicon esculentum.

\section{ABSTRACT}

This study was aimed at evaluating the effect of ripening stages and different storage temperature on the quality of 'Cronus' tomato. Treatments were combinations of ripening stages (partially ripe and ripe) and storage temperatures (6, 8, 10 and $\left.12^{\circ} \mathrm{C}\right)$. Fruits were stored in experimental chambers with $90 \%$ relative humidity. After 30 days of storage plus two days at $20^{\circ} \mathrm{C}$, interactions between the factors ripening stages and temperature of storage were not observed. Fruits stored at 6 and $8^{\circ} \mathrm{C}$ had higher firmness. However, in these temperatures the chilling injury, fruit cracking and rot incidence was higher. Total soluble solids and titratable acidity did not show significant difference among treatments. Fruits harvested at partially ripe stage showed the highest firmness and the lowest incidence of rot and cracking. Ripening stage did not affect the susceptibility to chilling injury.

Key words: postharvest, chilling injury, Lycopersicon esculentum.

\section{INTRODUÇÃO}

O tomate é um fruto muito perecível, sendo necessário o uso de tecnologias de conservação para retardar o seu amadurecimento, manter a sua qualidade e, conseqüentemente, prolongar a conservação. No entanto, poucos esforços têm sido empregados para garantir a qualidade pós-colheita, sendo perdida uma grande parte da produção de tomates (MOURA et al., 1999).

O armazenamento refrigerado, que consiste na redução da temperatura e no controle da umidade relativa, é um dos principais métodos utilizados para conservação de frutas e hortaliças, pois diminui o metabolismo celular, retardando a rápida deterioração. $\mathrm{O}$ amadurecimento do tomate envolve uma série de

\footnotetext{
IDepartamento de Fitotecnia, Universidade Federal de Santa Maria (UFSM), 97105-900, Santa Maria, RS, Brasil. E-mail: brackman@ccr.ufsm.br. Autor para correspondência.

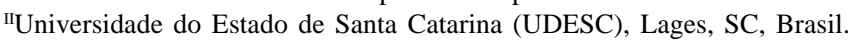

IIIfSM, Santa Maria, RS, Brasil.
} 
eventos fisiológicos coordenados que desencadeiam mudanças na pigmentação, no sabor, na firmeza de polpa e no aroma, sendo altamente influenciados pela temperatura à qual os frutos estão expostos (LURIE et al., 1996). MOURA et al. (1999) citam que a qualidade do tomate é definida por estas mudanças decorrentes do amadurecimento, sendo a firmeza de polpa o aspecto mais importante (DE KETELAERE et al., 2004). Alguns trabalhos referentes ao armazenamento refrigerado de tomate foram realizados; no entanto, não existem informações sobre o armazenamento refrigerado da cultivar "Cronus", que se caracteriza por ser do tipo longa vida e classificada como sendo do grupo oblongo.

A temperatura ótima de armazenamento do tomate depende do estádio de maturação, sendo que frutos verdes devem ser armazenados em temperaturas em torno de $13^{\circ} \mathrm{C}$, frutos parcialmente maduros em torno de $10^{\circ} \mathrm{C}$ e frutos maduros podem ser armazenados em temperaturas de $8^{\circ} \mathrm{C}$ (LUENGO \& CALBO, 2001). CANTWELL \& KASMIRE (2002) citam que tomates verdes devem ser armazenados em temperaturas iguais ou maiores que $12^{\circ} \mathrm{C}$, e tomates parcialmente maduros podem ser armazenados em temperaturas iguais ou superiores a $10^{\circ} \mathrm{C}$. JACKMAN et al. (1988) afirmam que o tomate é altamente suscetível ao dano causado por baixas temperaturas, não suportando temperaturas menores que $12^{\circ} \mathrm{C}$. O dano pelo frio é caracterizado pelo desenvolvimento de manchas escuras na epiderme, prejudicando a sua comercialização, sendo também um fator muito importante na avaliação da qualidade do tomate (LUENGO \& CALBO, 2001). CANTWELL \& KASMIRE (2002) citam que este distúrbio fisiológico ocorre quando os frutos são armazenados abaixo da temperatura recomendada e que a severidade do sintoma depende da temperatura e do tempo de exposição.

O estádio de maturação do tomate, além de definir a temperatura de armazenamento, influencia a vida pós-colheita, o processo de amadurecimento e, conseqüentemente, a qualidade do produto que chega ao consumidor (MOURA et al., 1999). Frutos colhidos verdes apresentam maior vida pós-colheita e maior resistência ao transporte; porém, normalmente são frutos de qualidade inferior àqueles colhidos com um estádio de maturação mais avançado. No entanto, apesar de os frutos colhidos maduros apresentarem uma qualidade sensorial superior, eles são muito perecíveis, possuindo uma vida pós-colheita muito curta. De acordo com MOURA et al. (1999), a situação ideal seria colher os frutos quando já tivessem atingido sua maturação fisiológica, de forma que não se comprometesse o amadurecimento e se permitisse ao produto uma boa qualidade durante o período de comercialização. Assim, a colheita de frutos parcialmente maduros ou maduros, juntamente com o armazenamento refrigerado, pode ser uma alternativa para se obter frutos de melhor qualidade, durante a comercialização, sem excessivas perdas de produto.

O objetivo deste trabalho foi avaliar o efeito da combinação de diferentes temperaturas de armazenamento e de estádios de maturação sobre a manutenção da qualidade do tomate cultivar “Cronus”.

\section{MATERIAL E MÉTODOS}

O experimento foi conduzido no Núcleo de Pesquisa em Pós-Colheita (NPP) do Departamento de Fitotecnia da Universidade Federal de Santa Maria, sendo que os tomates utilizados foram produzidos em ambiente protegido na área experimental do Departamento.

O armazenamento foi realizado em minicâmaras experimentais, com volume de 232 litros. O monitoramento das temperaturas de armazenamento foi feito diariamente, utilizando-se termômetros de mercúrio introduzidos na polpa de alguns frutos. A variação da temperatura foi de $\pm 0,2^{\circ} \mathrm{C}$.

O delineamento experimental utilizado foi o de blocos ao acaso, arranjado em um esquema bifatorial, com quatro repetições, sendo a unidade experimental composta por 18 frutos. Os oito tratamentos utilizados originaram-se da combinação de dois níveis do fator estádio de maturação, parcialmente maduro e maduro, com quatro níveis do fator temperatura de armazenamento, de 6, 8, 10 e $12^{\circ} \mathrm{C}$. Os frutos do estádio de maturação parcialmente maduro apresentavam de 30 até $50 \%$ da epiderme com coloração vermelha, e os frutos do estádio de maturação maduro estavam completamente vermelhos, mas ainda firmes.

Após o armazenamento refrigerado por 30 dias e mais dois dias de exposição à temperatura de $20^{\circ} \mathrm{C}$ em uma câmara de climatização, foram realizadas as análises de qualidade. A firmeza de polpa e a incidência de distúrbios fisiológicos foram determinadas em cada fruto, enquanto que os sólidos solúveis totais e a acidez titulável foram determinados no suco extraído das amostras de 18 frutos. A firmeza de polpa foi determinada em dois lados na parte equatorial do fruto, onde foi previamente retirada a epiderme, com auxílio de um penetrômetro motorizado com ponteira de $11 \mathrm{~mm}$ de diâmetro. O teor de sólidos solúveis totais foi determinado com auxílio de um refratômetro manual, com correção da temperatura. A acidez titulável foi determinada através de titulação de 10mL de suco diluídos em 100mL de água destilada, 
com solução de $\mathrm{NaOH} 0,1 \mathrm{~N}$ até pH 8,1. Na avaliação de ocorrência de podridões, os frutos com lesões de diâmetros superiores ou iguais a $0,5 \mathrm{~cm}$ e com características de ataques de patógenos foram considerados podres. A incidência de rachaduras foi determinada por meio da contagem de frutos com epiderme e/ou polpa rachados e a incidência de frutos com dano pelo frio foi avaliada pela contagem de frutos com manchas na epiderme. Os dados de incidência de podridão, rachaduras e dano pelo frio foram expressos em porcentagem, sendo transformados pela fórmula arcosen(x/100 antes de serem submetidos à análise da variância, juntamente com os dados dos demais parâmetros. Após a análise de variância, as médias do fator estádio de maturação foram comparadas pelo teste de Duncan e as médias do fator temperatura de armazenamento foram submetidas à análise de regressão, ambos em nível de 5\% de probabilidade de erro.

\section{RESULTADOS E DISCUSSÃO}

Após 30 dias de armazenamento mais dois dias de exposição dos frutos a $20^{\circ} \mathrm{C}$, os resultados da análise da variância não apresentaram significância para a interação entre os fatores estádio de maturação e temperatura de armazenamento em todos os parâmetros avaliados.

A firmeza de polpa, após 30 dias de armazenamento refrigerado mais dois dias a $20^{\circ} \mathrm{C}$, reduziu-se com o aumento da temperatura de armazenamento (Figura 1), sendo que os frutos parcialmente maduros apresentaram-se mais firmes que os frutos maduros (Tabela 1). Os resultados obtidos estão de acordo com os obtidos por LANA et al. (2005), que verificaram maior firmeza de polpa em frutos armazenados em temperaturas mais baixas e em frutos colhidos menos maduros. De acordo com BRUMMELL et al. (1999), a perda de firmeza de polpa em tomates está relacionada à perda de turgor, mas, principalmente, ao metabolismo da parede celular, ocorrendo uma extensiva despolimerização da pectina e hemicelulose e uma fraca despolimerização da celulose. LURIE et al. (1996) verificaram que tomates submetidos a baixas temperaturas apresentaram uma baixa capacidade de produzir etileno devido à redução na taxa de transcrição de mRNA para ACC oxidase e também na quantidade da enzima ACC oxidase. Os resultados obtidos por MAJUMDER \& MAZUMDAR (2002) e JOHNSTON et al. (2001), em maçã, demonstram que a presença do etileno é necessária para a atividade das enzimas responsáveis pela degradação da parede celular e, conseqüentemente, pela perda de firmeza do fruto.

A acidez titulável e os sólidos solúveis totais não foram influenciados pelo estádio de maturação dos frutos ou pela temperatura de armazenamento (Tabelas 1 e 2). Como estes parâmetros interferem diretamente no sabor dos frutos, estes resultados evidenciam que tomates colhidos parcialmente maduros ou maduros apresentam, após o armazenamento, independentemente da temperatura de armazenamento, uma qualidade semelhante em termos de sabor. De acordo com MOURA et al. (1999), frutos que sofrem o processo de amadurecimento na planta são preferidos pelos consumidores com relação ao sabor e cor dos frutos após a colheita, porém estes frutos são muito

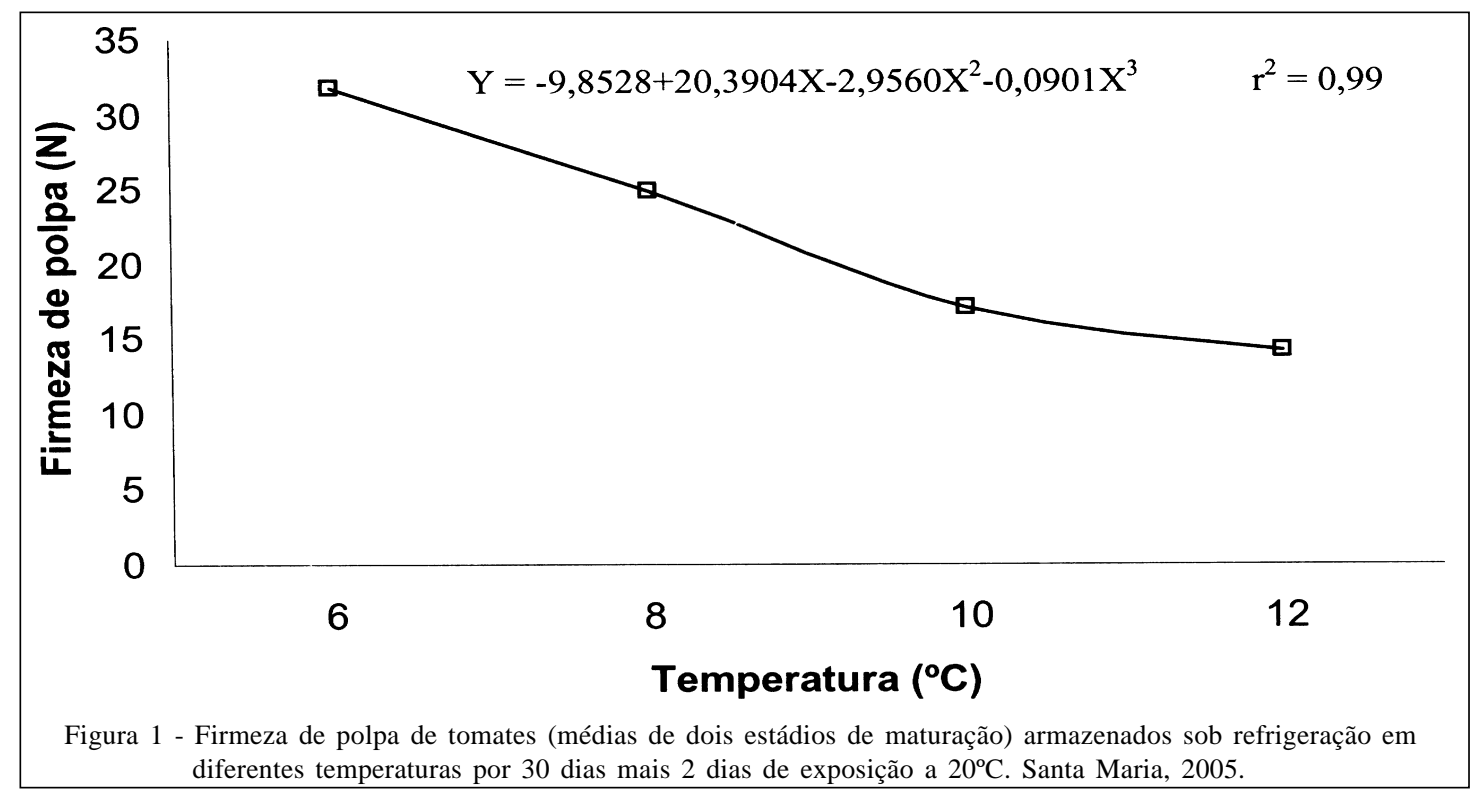

Ciência Rural, v.37, n.5, set-out, 2007. 
Tabela 1 - Efeito do estádio de maturação (médias de quatro temperaturas de armazenamento) sobre a qualidade de tomates armazenados sob refrigeração por 30 dias mais 2 dias de exposição a $20^{\circ} \mathrm{C}$. Santa Maria, 2005.

\begin{tabular}{|c|c|c|c|c|c|c|}
\hline $\begin{array}{l}\text { Estádio de } \\
\text { maturação }\end{array}$ & $\begin{array}{l}\text { Firmeza de polpa } \\
(\mathrm{N})\end{array}$ & $\begin{array}{l}\text { Acidez titulável } \\
\left(\text { cmol. } \mathrm{L}^{-1}\right)\end{array}$ & $\begin{array}{c}\text { Sólidos solúveis } \\
\text { totais ( }{ }^{\circ} \text { Brix) }\end{array}$ & Rachaduras (\%) & Podridões (\%) & $\begin{array}{c}\text { Dano pelo frio } \\
\text { (\%) }\end{array}$ \\
\hline $\begin{array}{l}\text { Parcialmente } \\
\text { maduro }\end{array}$ & $24,0 a^{*}$ & $4,57 a$ & $4,20 \mathrm{a}$ & $16,7 b$ & 29,9b & 31,9a \\
\hline Maduro & $19,0 \mathrm{~b}$ & $4,29 a$ & 3,96a & $36,4 a$ & $53,6 a$ & $33,4 a$ \\
\hline CV (\%) & 18,1 & 10,1 & 4,1 & 41,0 & 31,6 & 35,4 \\
\hline
\end{tabular}

*Tratamentos com médias seguidas de letras distintas diferem estatisticamente pelo teste de Duncan (5\%).

suscetíveis a perdas durante o armazenamento. Estes autores ainda citam que a situação ideal seria armazenar frutos de um estádio de maturação que não comprometesse o amadurecimento e permitisse ao produto uma boa qualidade durante o período de comercialização.

A incidência de rachaduras foi maior nos frutos armazenados maduros e nas temperaturas de 6 e $8^{\circ} \mathrm{C}$ (Tabela 1), havendo uma redução na incidência de rachaduras com o aumento da temperatura de armazenamento, independentemente do estádio de maturação dos frutos (Figura 2). De acordo com MATAS et al. (2005), frutos maduros são mais sensíveis à incidência de rachaduras do que frutos parcialmente maduros. Esses autores também verificaram que o aumento na temperatura reduz as propriedades de resistência mecânica da cutícula de tomates, deixandoos mais suscetíveis à rachadura, o que não ocorreu no presente trabalho. Talvez esta discordância entre resultados seja devida ao fato de que estes autores tenham estudado somente temperaturas acima de $10^{\circ} \mathrm{C}$, situação em que não ocorre dano pelo frio. Observouse que a incidência de rachaduras foi maior naquelas temperaturas em que houve maior incidência de dano pelo frio, podendo ter causado um enfraquecimento da cutícula na região onde ocorreu este distúrbio fisiológico.
A incidência de dano pelo frio, caracterizado pela formação de manchas escuras na epiderme, foi maior nos frutos armazenados a 6 e $8^{\circ} \mathrm{C}$ e não foi observada nos frutos armazenados a 10 e $12^{\circ} \mathrm{C}$ (Figura 2). Os resultados obtidos concordam com LURIE et al. (1996), SABEHAT et al. (1996) e CANTWELL \& KASMIRE (2002), que afirmam que o dano pelo frio ocorre em frutos armazenados em temperaturas menores que $10^{\circ} \mathrm{C}$, porém discordam de JACKMAN et al. (1988), que afirmam que temperaturas abaixo de $12^{\circ} \mathrm{C}$ já induzem a manifestação deste distúrbio fisiológico. Não foram verificadas diferenças entre frutos armazenados nos estádios de maturação parcialmente maduro e maduro, quanto à incidência de dano pelo frio (Tabela 1). LUENGO \& CALBO (2001) afirmam que tomates parcialmente maduros podem ser armazenados a $10^{\circ} \mathrm{C}$. No entanto, esses mesmos autores citam que frutos maduros suportam temperaturas de $8^{\circ} \mathrm{C}$, o que não foi observado neste trabalho.

A incidência de podridões foi menor nos frutos armazenados no estádio de maturação parcialmente maduro e nas temperaturas de 10 e $12^{\circ} \mathrm{C}$. De acordo com WILLS et al. (1981), frutos imaturos são menos suscetíveis à ocorrência de podridões que frutos maduros, concordando com os resultados obtidos neste trabalho. KLUGE et al. (1996) também observaram menor incidência de podridões em frutos

Tabela 2 - Efeito da temperatura (médias de dois estádios de maturação) sobre a qualidade de tomates cv. “Cronus” armazenados por 30 dias sob refrigeração mais 2 dias de exposição a $20^{\circ} \mathrm{C}$. Santa Maria, 2005.

\begin{tabular}{|c|c|c|c|c|c|c|}
\hline Temperatura $\left({ }^{\circ} \mathrm{C}\right)$ & $\begin{array}{l}\text { Firmeza de polpa } \\
\text { (N) }\end{array}$ & $\begin{array}{l}\text { Acidez titulável } \\
\quad\left(\mathrm{cmol} . \mathrm{L}^{-1}\right)\end{array}$ & $\begin{array}{c}\text { Sólidos solúveis } \\
\text { totais }\left({ }^{\circ} \mathrm{Brix}\right)\end{array}$ & Rachaduras (\%) & Podridões (\%) & Dano elo frio (\%) \\
\hline 6 & 31,7 & 4,58 & 4,30 & 56,9 & 66,7 & 98,6 \\
\hline 8 & 23,1 & 4,44 & 4,18 & 25,2 & 41,1 & 31,4 \\
\hline 10 & 17,0 & 4,59 & 4,16 & 8,3 & 28,8 & 0,0 \\
\hline 12 & 14,0 & 4,25 & 4,19 & 12,5 & 30,5 & 0,0 \\
\hline Média & $21,4^{*}$ & $4,46^{\mathrm{ns}}$ & $4,21^{\mathrm{ns}}$ & $25,7^{*}$ & $41,8^{*}$ & $32,5^{*}$ \\
\hline CV (\%) & 18,1 & 10,1 & 4,1 & 41,0 & 31,6 & 35,4 \\
\hline
\end{tabular}

* - regressão linear, quadrática e/ou cúbica significativa em nível de 5\% de probabilidade de erro;

ns - regressões não-significativas.

Ciência Rural, v.37, n.5, set-out, 2007. 


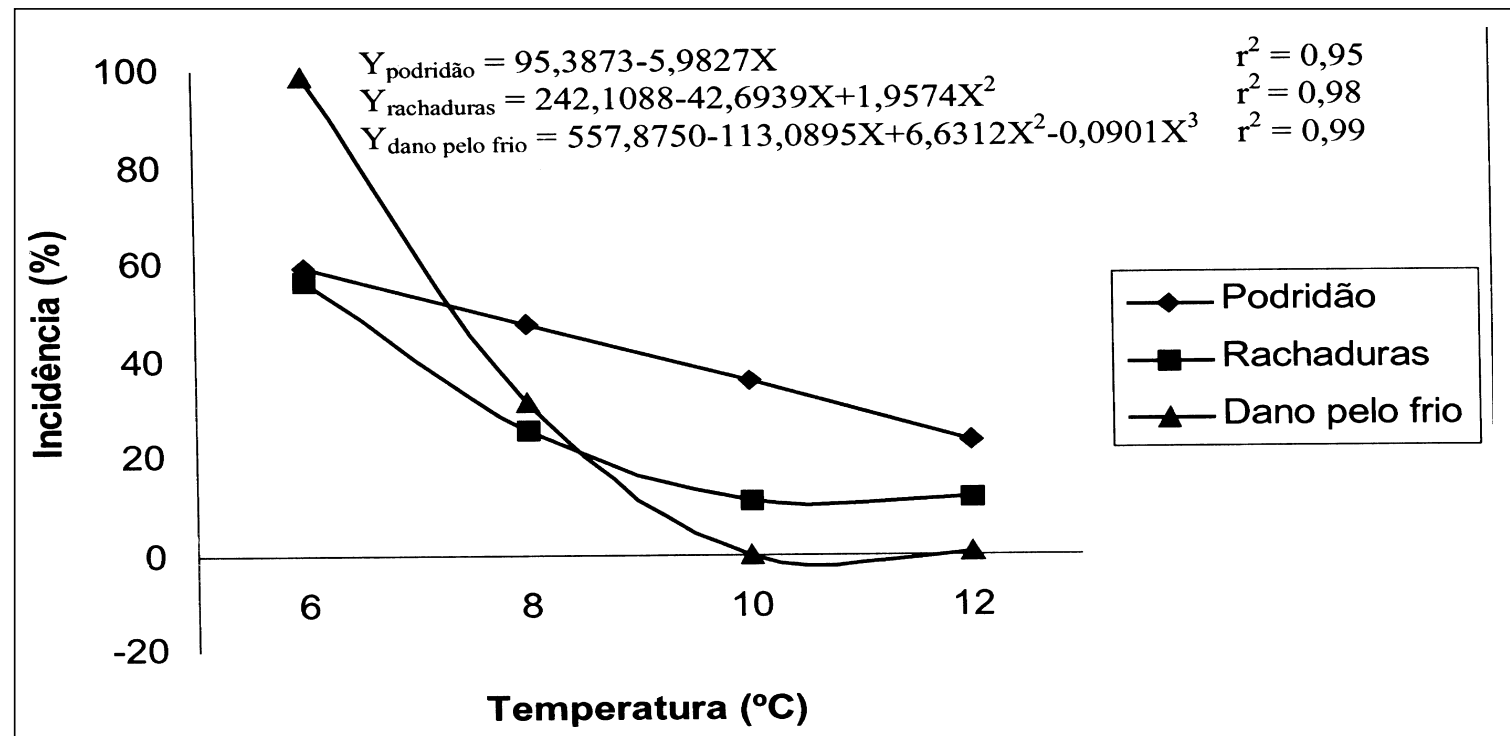

Figura 2 - Incidência de podridão, rachaduras e dano pelo frio em tomates (médias de dois estádios de maturação) armazenados sob refrigeração em diferentes temperaturas por 30 dias mais 2 dias de exposição a $20^{\circ} \mathrm{C}$. Santa Maria, 2005.

colhidos menos maduros. BRACKMANN \& SAQUET (1995) afirmaram que frutos em estádio mais avançado de amadurecimento apresentam pouca resistência à penetração e ao desenvolvimento dos patógenos. Esta afirmação sustenta os resultados deste trabalho, pois os frutos do estádio de maturação parcialmente maduro apresentavam maior firmeza de polpa do que aqueles maduros. No entanto, a mesma explicação não pode ser utilizada para o efeito da temperatura de armazenamento, pois os frutos armazenados a 6 e $8^{\circ} \mathrm{C}$ apresentaram maior firmeza de polpa e maior incidência de podridões. Provavelmente, mesmo com maior firmeza de polpa, os frutos armazenados nestas temperaturas apresentem maior suscetibilidade à infecção devido à incidência de rachaduras na sua epiderme, pois o processo de infecção, principalmente na fase póscolheita, é facilitado pela ocorrência de danos mecânicos na epiderme dos frutos (WILLS et al., 1981).

\section{CONCLUSÃO}

O tomate cultivar "Cronus” deve ser colhido parcialmente maduro com 30 a 50\% da epiderme vermelha, pois, após o armazenamento, apresenta maior firmeza de polpa e menor incidência de rachadura e podridões. Este tomate deve ser armazenado na temperatura de $10^{\circ} \mathrm{C}$, uma vez que os frutos não desenvolvem dano pelo frio e apresentam menor ocorrência de podridões e rachaduras.

\section{REFERÊNCIAS}

BRACKMANN, A.; SAQUET, A.A. Armazenamento de maçã cv. Gala em atmosfera controlada. Revista Brasileira de Agrociência, Pelotas, v.1, n.2, p.55-60, 1995.

BRUMMELL, D.A. et al. Modification of expansin protein abundance in tomato fruit alters softening and cell wall polymer metabolism during ripening. Plant Cell, Rockville, v.11, n.11, p.2203-2216, 1999.

CANTWELL, M.I.; KASMIRE, R.E. Postharvest handling systems: fruit vegetables. In: KADER, A.A. Postharvest technology of horticultal crops. Oakland: University of California, 2002. p.407-421.

DE KETELAERE, B. et al. Tomato cultivar grouping based on firmeness change, shelf life and varíense during postharvest storage. Postharvest Biology and Technology, Amsterdam, v.34, p.187-201, 2004.

JACKMAN, R.L. et al. Chilling injury. A review of quality aspects. Journal of Food Quality, Trumbull, v.11, n.4, p.253278, 1988.

JOHNSTON, J.W. et al. Temperature induces differential softening responses in apple cultivars. Postharvest Biology and Technology, Amsterdam, v.23, n.3, p.185-196, 2001.

KLUGE, R.A. et al. Influência do estádio de maturação e da cobertura com polietileno na conservação de tomates frigorificados. Scientia Agrícola, Piracicaba, v.53, n.1, p.613, 1996.

LANA, M.M. et al. Effects of storage temperature and fruit ripening on firmness of fresh cut tomatoes. Postharvest Biology and Technology, Amsterdam, v.35, p.87-95, 2005. 
LUEnGO, R.F.A.; CALBO, A.G. Armazenamento de hortaliças. Brasília:Embrapa Hortaliças, 2001. 242p.

LURIE, S. et al. Reversible inhibition of tomato fruit gene expression at high temperature. Plant Physiology, Rockville, v.110, n.4, p.1207-1214, 1996

MAJUMDER, K.; MAZUMDAR, B.C. Changes of pectic substances in developing fruits of cape-gooseberry (Physalis peruviana L.) in relation to the enzyme activity and evolution of ethylene. Scientia Horticulturae, Amsterdam, v.96, n.14, p.91-101, 2002.

MATAS, A.J. et al. Relative humidity and temperature modify the mechanical properties of isolated tomato fruit cuticles.
Amercian Journal of Botany, Saint Louis, v.92, n.3, p.462468, 2005.

MOURA, M.L. et al. Efeito da atmosfera controlada na conservação de tomates colhidos em estádio intermediário de maturidade. Scientia Agrícola, Piracicaba, v.56, n.1, p.135142, 1999.

SABEHAT, A. et al. The correlation between heat-shock protein accumulation and persistence and chilling tolerance in tomato fruit. Plant Physiology, Rockville, v.110, n.3, p.531537, 1996.

WILLS, R.H.H. et al. Postharvest: an introduction to the physiology and handling of fruit and vegetables. Granada: London, 1981. 163p. 